\title{
Efficacy of Fetal Stem Cells use in Complex Treatment of Patients with Insulin-resistant Type 2 Diabetes Mellitus
}

Dr. Mariya Demchuk*, Dr. Olena Ivankova, Dr. Mariya Klunnyk, Dr. Iryna Matiyashchuk, Dr. Nataliia Sych, Dr. Andriy Sinelnyk, Dr. Alla Novytska and Khrystyna Sorochynska

Cell Therapy Center EmCell, Kyiv City,Ukraine

\begin{abstract}
Objective: To identify efficacy of fetal stem cells in treatment of the patients suffering from Type 2 diabetes mellitus in presence of insulin resistance and to summarize all characteristics of post-transplantation disease course.

Materials and methods: 42 patients suffering from Type 2 diabetes mellitus (T2DM) in presence of insulin resistance were examined including 27 men and 15 women. Glycaemia ranges were controlled by diet therapy in 7 patients $(16.7 \%)$, whereas the rest of the patients were recommended antihyperglycemic medicines (biguanides, thiazolidinediones, sulfonylurea derivatives and $\alpha$-reductase inhibitors). Fetal stem cells (FSCs) were administered in complex therapy for the patients with T2DM and the data of clinical, laboratory and anthropometric investigations were analyzed over the study period.
\end{abstract}

Results: Positive effects to values of carbohydrate and lipid metabolism, as well as arterial blood pressure (ABP) in T2DM have been justified. FSCs capacity to decreasing insulin resistance (in accordance with the HOMA-IR scale) which results in stable continuous diabetes mellitus compensation was established.

Conclusion: FSCs use in complex treatment of patients with T2DM stabilizes disease compensation and leads to decrease in hyperinsulinemia and lower insulin resistance.

Keywords: Fetal stem cells; Insulin resistance; Treatment of type 2 diabetes mellitus

\begin{abstract}
Abbreviations: T2DM: Type 2 Diabetes Mellitus; FSCs: Fetal Stem Cells; IR: Insulin Resistance; HOMA: Homeostasis Model Assessment HbA1c: Glycated Hemoglobin; LDL-C: Low Density Lipoprote in Cholesterol Level; VLDL-C: Very Low Density Lipoprotein Cholesterol Level; HDL-C: High Density Lipoprotein Cholesterol Level; TG: Triglycerides; PFI: Plasma Fasting Insulin; PFG: Plasma Fasting Glucose; IHD: Ischemic Heart Disease; ABP: Arterial Blood Pressure; SBP :Systolic Blood Pressure; DBP: Diastolic Blood Pressure; BMI: Body Mass Index; WC: Waist Circumference; DMSO : Dimethyl Sulfoxide; CLIA: Chemiluminescent Immunoassay; ECLIA: Immunochemical Method With ECL Detection; IDF: International Diabetes Federation
\end{abstract}

\section{Introduction}

Diabetes mellitus (DM) is a markedly spread endocrine illness worldwide, which has already grown into a non-infectious epidemic. In accordance with the data of World Health Organization (WHO) and International Diabetic Federation (IDF) in 2015 diabetes prevalence reached 415 million persons all over the world [1,2], and with relation to disease incidence rates, the number of patients can amount as many as 592 million persons until 2035 [3]. T2DM specific gravity comprises from 85 to $90 \%$ among all cases of this disease. As far as often DM disease cannot be diagnosed over the years due to lack of hyperglycemia symptoms - subsequently, the patients would often suffer 1-2 disease complications prior to T2DM diagnosis could be confirmed in the patient [4]. In the first instance, early invalidity and high mortality rates among T2DM patients are induced by development of vascular complications. Approximately $80 \%$ of the patients with T2DM are suffering from arterial hypertension - their life span is threefold lower compared to this disease prevalence among the healthy population. Spread of ischemic heart disease (IHD) along with associated T2DM illness is 2-4 times more frequent among the patients; the risk of acute myocardial infarction increases 6-10 times and acute disturbances of cerebral circulation - are 4-7-fold more often in comparison with the same problems in the patients without DM $[5,6]$.

Disruption of insulin secretion by $\beta$-cells of pancreatic islets of Langerhans and low resistance to insulin in peripheral tissues insulin-resistance (IR) have been outlined as the principal mechanisms for T2DM development. In particular, IR is considered to be a pathophysiology background for T2DM as the main mechanism which defines appearance of associated disturbances in metabolism of carbohydrates and lipids as well as disorders of arterial blood pressure (ABP) and endothelial dysfunctions [7,8]. The above mentioned disorders tend to cause fast arteriosclerosis development and high mortality rates which are superimposed by cardiovascular diseases among the patients suffering from T2DM [9].

The basic metabolic changes of IR are associated with decrease of insulin physiological function at the cellular level. Hyperglycemia emerges resulting from decreased reuptake of glucose in peripheral tissues and enhanced gluconeogenesis along with elevation of glucose produced by the liver. Hyperlipidemia is the result of decreased fatty acids synthesis and lipolysis stimulation with accumulation of free fatty acids (FFA) in blood plasma, which are likely to become a source of building-up atherogenic very low-density lipoproteins (VLDL),

*Corresponding author: Dr. Mariya Demchuk, Internal Medicine, Cell Therapy Center EmCell, Kyiv City,Ukraine, Tel: 380672331982; +38 0672362761 E-mail: infocenter@emcell.com

Received April 17, 2016; Accepted June 20, 2016; Published June 27, 2016

Citation: Demchuk MP, Ivankova O, Klunnyk M, Matiyashchuk I, Sych N, et al. (2016) Efficacy of Fetal Stem Cells use in Complex Treatment of Patients with Insulin-resistant Type 2 Diabetes Mellitus. J Stem Cell Res Ther 6: 342. doi:10.4172/2157-7633.1000342

Copyright: @ 2016 Demchuk MP, et al. This is an open-access article distributed under the terms of the Creative Commons Attribution License, which permits unrestricted use, distribution, and reproduction in any medium, provided the original author and source are credited. 
Citation: Demchuk MP, Ivankova O, Klunnyk M, Matiyashchuk I, Sych N, et al. (2016) Efficacy of Fetal Stem Cells use in Complex Treatment of Patients with Insulin-resistant Type 2 Diabetes Mellitus. J Stem Cell Res Ther 6: 342. doi:10.4172/2157-7633.1000342

Page 2 of 7

triglycerides (TG) inside of hepatocytes and is a consequence of decreased atherogenic elimination of VLDL lipoproteins - and lowdensity lipoproteins (LDL). Besides, dyslipidemia develops because of decreased high-density lipoproteins cholesterol levels (HDL-C) since those require apoproteins and phospholipids which are released from VLDL and LDL during lipolysis. FFA supplied to systemic blood circulation disrupt all functions of insulin receptors and intensify IR (lipotoxicity effect).

IR induces compensatory hyperproduction of insulin by $\beta$-cells of pancreatic islets of Langerhans and results in persistent and stable hyperinsulinemia. It has been experimentally proved that insulin exerts its immediate atherogenic effects on the walls of vessels by stimulating proliferation and migration of nonstriated myocytes, growth of fibroblasts, activation of blood coagulation system, and decreased performance of fibrinolysis. Thus, high blood insulin levels contribute to appearance and progression of arteriosclerosis in the patients with DM.

Hyperinsulinemia tends to be a marker of IR and is commonly detected at onset of T2DM disease. With the lapse of time, when IR rate increases - capacity for insulin production by the $\beta$-cells of pancreatic islets of Langerhans is exhausted. Primarily, function of fast secretion of postprandial insulin is affected (phase 1 of insulin secretion) whereas 2 phase (phase of basal insulin secretion) remains surplus. High blood glucose level enhances IR in peripheral tissues and diminishes insulin secretory function by $\beta$-cells - and, in fact, reveals its glucose toxicity. On average over 10-15 years after diagnosis-making, the patients may experience stable hypoinsulinemia which requires prescription of replacement therapy and insulin administration $[10,11]$.

In view of established by the world diabetes science mechanisms of T2DM genesis there have been changes in regard to treatment of DM patients. The main aim is to decrease the risks of vascular complications and promote a likelihood of longer life expectancy among the patients. In conformity with recommendations from American Diabetes Association (ADA) concerning T2DM (2011), it is reasonable to prescribe antihyperglycemic medicines in tablets only if diet therapy fails, notably, non-judicious medicines use must be avoided - this can stimulate hyperinsulinemia. In case of necessary selection of peroral antihyperglycemic preparation to achieve disease compensation, doctors prefer medicines which not only induce hypoglycemic effects, but also do not lead to marked hyperinsulinemia (III generation sulphonylurea preparations), or those resulting in lowering of blood glucose levels to some extent only, especially, medicines which decrease the rates of IR (biguanides, thiazolidinediones). Management of DM patients besides evaluation of carbohydrates metabolism suggests obligatory control of lipids profile by use of drug-free correction and continuous adjustment of hyperlipidemia and BP levels using medical drugs $[12,13]$.

Fetal stem cells (FSCs) treatment using cell suspensions has been recently used with confidence in diabetes science as a method of therapy for DM patients [14]. Among various advantages of FSCs treatment hypoglycemic effects have been mainly defined. In 2002 experimental study by Shiroi A., Yoshikawa M. (Japan) identified that at the stages of embryogenesis FSCs of mice synthesize insulin and substances with insulin-mimetic action exerting their proximate antihyperglycemic effect. Besides, these cells can differentiate into $\beta$-cells of pancreatic islets of Langerhans which induce not polipotent, but rather pluripotent effects [15]. Since 1991 the treatment methods for different types of DM using FSCs have been established by us; both indications and contraindications for FSCs use have been developed
[14-17], and eventually treatment proved its high effectiveness for type $1 \mathrm{DM}$ (T1DM) [18-22] and T2DM on different stages of the disease $[23,24]$. Effective FSCs application for metabolic syndrome has been recently recorded [25].

\section{Materials and Methods}

\section{Patients}

A group of patients suffering from T2DM was under study after administration of FSCs. Diabetes disease was defined according to the 1999 WHO diagnostic criteria [26]. The study was conducted in accordance with good clinical practice, Helsinki declaration as well as the ethical standards for work with human embryonic tissues approved by the Ministry of Health of Ukraine [27]; methodology recommendations at the Ministry of Health of Ukraine, Academy of Medical Science of Ukraine, Ukrainian Center for Scientific Medical Information and Patent Licensing on treatment of patients with diabetes mellitus [28]. All the patients gave their informed consent prior to treatment. Study group included 42 patients with T2DM: 27 men and 15 women whose mean age made up $56.7 \pm 6.3$ years (Table 1).

Clinical observation and examination of the patients was performed during 1 year. In the clinical group disease duration after diagnosis making and right before FSCs transplantation constituted from 6 months up to 3.5 years $(2.7 \pm 0.5$ yrs. on average). Elevation of body weight was recorded among the patients. Body mass index (BMI) ranged from 29.3 to $36.7 \mathrm{~kg} / \mathrm{m}^{2}$, the mean value made up 34.49 $\pm 2.81 \mathrm{~kg} / \mathrm{m}^{2}$. Before FSCs use 8 patients (19\%) were administered diet therapy only, the rest of patients received antihyperglycemic agents per os (biguanides, thiazolidinediones, sulfonylurea derivatives, and $\alpha$-reductase inhibitors). No modification in treatment regimen and medicines volume was recorded among all patients undergoing treatment within the last 3 years. Stable morning hyperglycemia has been observed in all patients (from 7.8 to $10.1 \mathrm{mmol} / \mathrm{L} ; 8.73 \pm 0.64$ $\mathrm{mmol} / \mathrm{L}$ on average) within the range of postprandial blood glucose from 8.1 to $14.9 \mathrm{mmol} / \mathrm{L}, 11.23 \pm 1.96 \mathrm{mmol} / \mathrm{L}$ on average. The level of HbAlc composed $8.31 \pm 1.60 \%$ on average. The changes in blood lipid profile with increased cholesterol level over $34.6 \%$ on average;

\begin{tabular}{|c|c|c|}
\hline Parameters & Patients with T2DM & Healthy individuals \\
\hline Number of patients, sex (m/w) & $42(27 / 15)$ & 19 \\
\hline Age, years & $56.7 \pm 6.3$ & $53.4 \pm 3.7$ \\
\hline Duration of presented signs & $2.7 \pm 0.5$ & - \\
\hline $\mathrm{WC}, \mathrm{cm}(\mathrm{m} / \mathrm{w})$ & $\begin{array}{c}113.24 \pm 10.65 / 101.24 \\
\pm 9.73\end{array}$ & $\begin{aligned} 90.24 & \pm 4.37 / 77.62 \\
& \pm 4.25\end{aligned}$ \\
\hline Body mass index (BMI), $\mathrm{kg} / \mathrm{m}^{2}$ & $34.49 \pm 2.81$ & $23.67 \pm 2.42$ \\
\hline $\begin{array}{l}\text { Fasting glycemic index (GI), } \\
\mathrm{mmol} / \mathrm{L}\end{array}$ & $8.73 \pm 0.64$ & $4.71 \pm 1.08$ \\
\hline $\begin{array}{l}\text { Fasting insulinemia score, } \\
\mathrm{mcU} / \mathrm{mL}\end{array}$ & $27.81 \pm 6.2$ & $10.37 \pm 1.35$ \\
\hline C-peptide levels, ng/mL & $6.84 \pm 1.87$ & $1.98 \pm 0.48$ \\
\hline $\mathrm{HbA} 1 \mathrm{c}, \%$ & $8.31 \pm 1.60$ & $4.92 \pm 1.23$ \\
\hline HOMA- IR & $8.13 \pm 1.28$ & $2.14 \pm 0.31$ \\
\hline Cholesterol, $\mathrm{mmol} / \mathrm{L}$ & $7.01 \pm 0.36$ & $4.76 \pm 0.23$ \\
\hline Triglycerides (TG), mmol/L & $2.01 \pm 0.45$ & $1.04 \pm 0.09$ \\
\hline $\mathrm{HDL}, \mathrm{mmol} / \mathrm{L}(\mathrm{m} / \mathrm{w})$ & $\begin{array}{c}0.72 \pm 0.14 / 0.90 \pm \\
0.08\end{array}$ & $\begin{array}{c}1.37 \pm 0.34 / 1.42 \pm \\
0.16\end{array}$ \\
\hline LDL, mmol/L & $5.23 \pm 0.74$ & $2.36 \pm 0.67$ \\
\hline VLDL, $\mathrm{mmol} / \mathrm{L}$ & $1.14 \pm 0.19$ & $0.63 \pm 0.28$ \\
\hline
\end{tabular}

Table 1: Clinical and laboratory characteristics of the patients. 
an elevation of LDL-C and VLDL-C concentration over mean $34 \%$ and $28 \%$ were recorded respectively, and the range of HDL-C in the patients decreased by $25 \%$. Blood serum C-peptide level increased from 4.83 to $8.36 \mathrm{ng} / \mathrm{mL}$ and on average these ranges made up $6.84 \pm 1.87$ $\mathrm{ng} / \mathrm{mL}$. All patients reported mean fasting hyperinsulinemia of $27.81 \pm$ $6.2 \mathrm{mcU} / \mathrm{mL}$ and laboratory evidences of insulin resistance: HOMAIR value ranged from 4.95 to $9.34(8.13 \pm 1.28$ on average). Disease clinical manifestations were not significant in regard to functional disorders and psychophysiology reactions in 10 patients $(23.8 \%)$; 32 patients $(76.2 \%)$ were presented with I-II stage hypertension, 9 patients $(21.4 \%)$ - IHD, 6 patients $(14.3 \%)$ - suffered from diseases of peripheral arteries. In accordance with the indications and following the recommendations of IDF (2012) [29], the patients underwent the following drugs therapy: angiotensin converting enzyme inhibitors or angiotensin receptor blockers, diuretics, calcium channel blockers, $\beta$-blockers, antiaggregants, and statins.

The parameters of carbohydrates metabolism. Plasma fasting glucose (PFG) levels and postprandial glucose were measured using the method of hexokinase enzyme system (reference range, 3,88-6,38 mmol/L); glycated hemoglobin (HbAlc) - by use of immunoturbidimetric technique (reference range, 4,8-5,9\%); plasma fasting insulin (PFI) levels were controlled by immunochemical method with ECL detection (ECLIA), (reference range, 2,6-24,9 mcU/mL) - Cobas 6000 automated analyzer using the testing systems of Roche Diagnostics (Switzerland); $\mathrm{C}$-peptide blood serum level was determined by indirect double stage chemiluminescent immunoassay (CLIA) (reference range, 0,8-4,2 $\mathrm{ng} / \mathrm{mL}$ ) - Liason automated analyzer by application of DiaSorin test systems (Italy). The value of insulin resistance was identified by use of HOMA (Homeostasis Model Assessment) method according to the following formula: HOMA-IR = fasting plasma insulin $(\mathrm{mcU} / \mathrm{mL}) \times$ fasting plasma glucose $(\mathrm{mmol} / \mathrm{L}) / 22.5$ [30], (reference range $<3$ ).

The parameters of lipid metabolism. Serum total cholesterol (TC), TG, HDL-C, LDL cholesterol (LDL-C) levels were measured by use of enzymatic methods adapted to Cobas 6000 analyzer with application of the testing systems of Roche Diagnostics (Switzerland). VLDL cholesterol (VLDL-C) level was calculated according to the Friedewald formula [31].

\section{Stem cell procedure}

A single application of cryopreserved fetal stem cell suspensions was conducted for the patients. The FSCs were received from the tissues of human cadaveric embryos with 5-8 weeks of gestation as a result of legal abortion due to family planning reasons and social indications. Collection of aborted material was performed in accordance with ethical-moral and legislation principles of work with biological tissues [27].

All donors of abortive material were practically healthy women who appeared negative to all hemic infections. Tissue was collected upon a written informed consent of the woman donor. Biotechnology process of suspensions preparation consisted in cells extraction from different growth zones of fetus, evaluation of cells viability and programmed cryopreservation, bacteriology and virology studies. In order to ensure safety, both women-donors and readily-made fetal stem cells were tested for parasites, mycotic, bacterial and viral infections such as human immunodeficiency virus 1 and 2, hepatitis B virus, hepatitis C virus, syphilis (Treponema pallidum), toxoplasmosis (Toxoplasma gondii), rubella, cytomegalovirus, herpes simplex virus 1 and 2, Epstein-Barr virus, Mycoplasma genitalium, Ureaplasma urealyticum, Ureaplasma parvum, and Chlamydia trachomatis.
Cryopreservation was made by means of $5 \%$ dimethyl sulfoxide (DMSO) cryoprotectant following a three-stage program for freezing at the rate of $1{ }^{\circ} \mathrm{C} / \mathrm{min}$ and crystal forming initiation in the controlledrate freezer chamber (Ice Cube 14S, SY-LAB Geräte GmbH). Suspensions containing stem cells were placed into liquid nitrogen at $-196^{\circ} \mathrm{C}$ for storage in a well-equipped cryobank. Water bath thawing of cryopreserved suspension at $37,5^{\circ} \mathrm{C}$ was performed immediately before cells administration. Fetal stem cells viability was tested by trypan blue staining and cells were counted using 2 methods in parallel: Goryaev chamber and Automated Cell Counter NC-100 (Nucleo Counter Type 900-004 Chemo Metec, Denmark 2010). Cells viability before freezing made up $83.0 \pm 3.0 \%$; after cryopreservation and water bath thawing the same rate accounted not less than $74.8 \pm 1.03 \%$. CD34+ levels were calculated by application of flow cytofluorometry (Becton Dickinson, Franklin Lakes, NJ, USA) with fluorescent tagged antibodies (Santa Cruz Biotechnology, Dallas, TX, USA).

The mode of administration - drip intravenous infusion, in volume from 0.5 to $3.0 \mathrm{~mL}$, with cells concentration from 1.0 to $100 \times 10^{6} /$ $\mathrm{mL}$, and values of CD34+ progenitor cells made up from 1 up to 20 $\times 10^{5} / \mathrm{mL}$.

\section{Statistics}

The results were statistically processed by use of software Statistica v.6.0 (StatSoft Inc., Tulsa, USA) with assessment of the mean values and standard deviation. Significant difference between the scores was calculated by application of the Students t-test. $\mathrm{P}<0.05$ was considered as statistically significant deviation.

\section{Results and Discussion}

All patients successfully tolerated FSCs treatment and no complications were reported. 36 patients (85.7\%) observed manifestations of syndrome of early post-transplantation improvements: decreased weakness, increased physical and mental capacity, better concentration, stabilization in sleep patterns, improved mood and decrease of depression events. Treatment results were more marked during the first 2-4 weeks; later effects insignificantly diminished and were preserved over 2-4 months. Over the first week after FSCs use 18 patients (42.9\%) reported increased blood glucose levels by $15-25 \%$. Hyperglycemia tended to decrease even without supplementary antihyperglycemic therapy. Later the parameters of glycaemia gradually dropped down among the patients (Figure 1) which demanded subsequent taper of medicines. No evidence of severe hypoglycemic response was reported by the patients.

Tendency to decreased fasting blood glucose levels was demonstrable over 2-3 months of observation $(8.09 \pm 0.65 \mathrm{mmol} / \mathrm{L}$ on average, $\mathrm{p}>0.05$ ). Likelihood of decreased fasting glycaemia levels was also revealed over 5-7 months after treatment and on average made up $6.73 \pm 0.42 \mathrm{mmol} / \mathrm{L}(\mathrm{p}<0.05)$; still remaining preserved for the total period under observation. The level of postprandial hyperglycaemia was likely decreased over 5-7 months of the study. 27 patients $(64.3 \%)$ reported 1.5-2-fold lowering in doses of hypoglycemic medicines over 4-6 months after FSCs administration. Gradual decrease in HвA1c levels happened simultaneously to improved values of blood glucose (Figure 2).

The similar decrease was observed over 2-3 months $(7.73 \pm 0.62 \%$ on average, $\mathrm{p}>0.05)$, with stabilization of this score in 32 patients (76.2\%) over 5-7 months of the study $(6.46 \pm 0.67 \%$ on average, $p<0.05)$ and within the next months of observation (on average $6.13 \pm 0.82 \%$, $\mathrm{p}<0.05$ ). It is worth to sum up that FSCs capacity to influence blood 


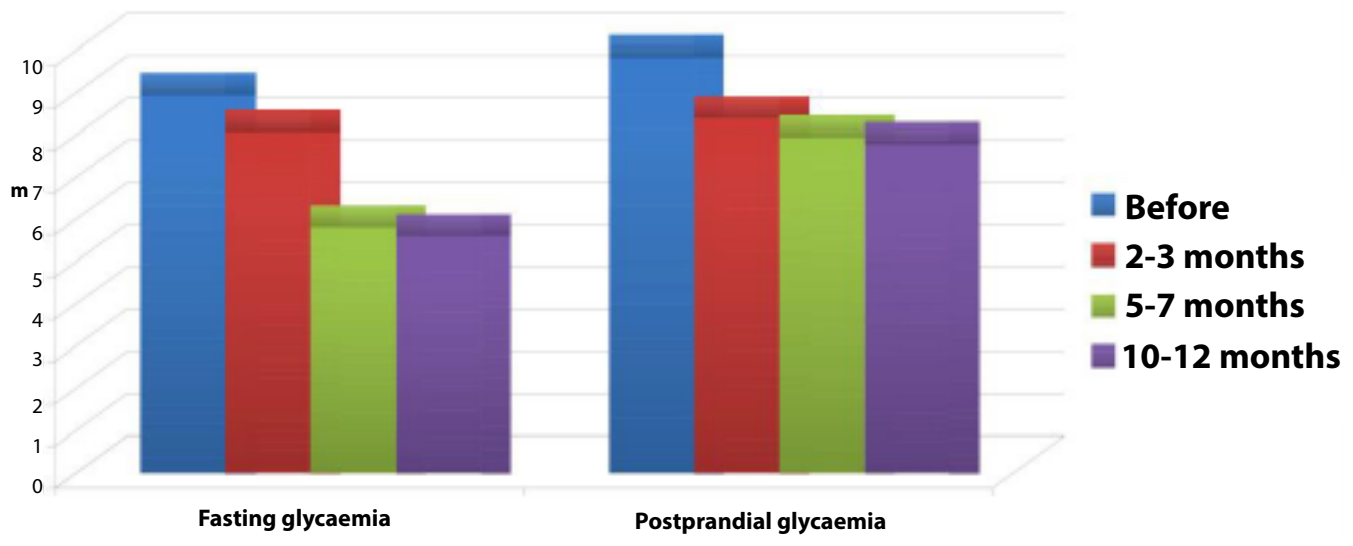

Figure 1: Glycaemia Dynamics before and after FSCs treatment in patients with Type 2 DM.

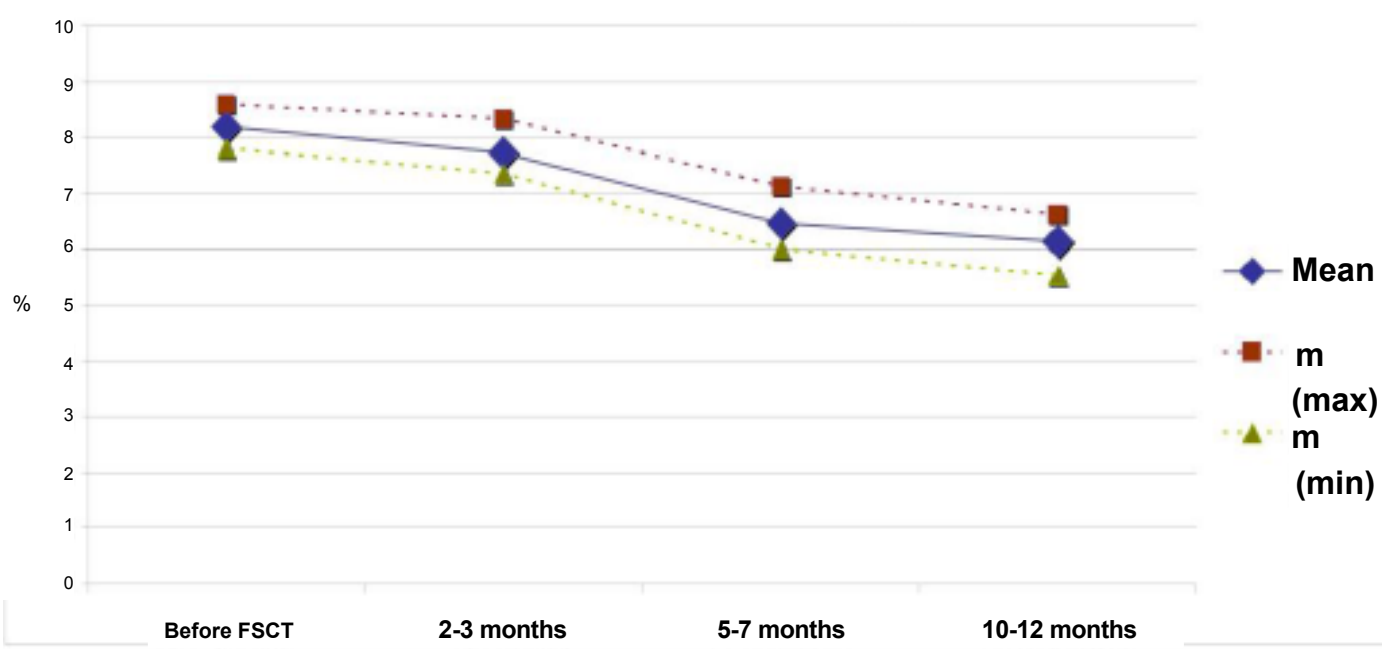

Figure 2: HbA1c Dynamics Before- and After FSCs Treatment in Patients with Type 2 DM.

glucose parameters in DM patients is clinically significant since $1 \%$ decrease of glycated hemoglobin value has been proved to result in $21 \%$ lower diabetes mortality rates; acute myocardial infarction risks decreased over $14 \%$; microvascular complications - over $37 \%$, and $47 \%$ lower mortality resulting from diseases of peripheral arteries were reported [32,33].

During analysis of insulin susceptibility among 39 patients in the group under study $(92.9 \%)$ decrease in parameter of HOMA-IR was demonstrable: over 2-3 months after FSCs transplantation by 1.5-1.7fold ( $4.91 \pm 0.38$ on average, $\mathrm{p}<0.05$ ), and as much as 2.4 -2.6-fold over 5-7 months $(3.1 \pm 0.96$ on average, $\mathrm{p}<0.05)$ and was the same until the end of the year under observation (Figure 3 ).

Decreased parameter of blood serum C-peptide in patients was shown over 2-3 months under observation (on average by $4.92 \pm 0.53$, $\mathrm{p}<0.05)$ the same value was stable in 32 patients $(76.2 \%)$ over $5-7$ months $(3.22 \pm 0.41$ on average, $\mathrm{p}<0.05)$ and over $10-12$ months $(2.92$ \pm 0.35 on average, $\mathrm{p}<0.05$ ) (Figure 4 ).

During assessment of lipids metabolism values, the next positive changes were also reported: within 10-12 months after FSCs transplantation 34 patients (81\%) demonstrated low levels of cholesterol, TG, LDL and VLDL cholesterol - by 20-24\%, and elevation of HDL cholesterol by 21-25\% was characteristic (Figure 5).

Waist circumference (WC) and excessive body weight have been known as absolute risk factors of cardiovascular diseases development [34]. Favorable changes were observed in 36 patients within the study group $(85.7 \%)$ in respect to lowering of body weight, BMI and WC over 12 months after FSCs treatment (Table 2).

FSCs induce a favorable effect on ABP in patients with T2DM. The parameters of systolic (SBP) and diastolic (DBP) arterial blood pressure were gradually decreased over 2-3 months after treatment by FSCs in $83.4 \%$ of patients. Steady stabilization of ABP levels which reached the target ranges was observed over 10-12 months after cells administration (Table 2). Volume of antihypertensive medicines therapy (quantity of medical drugs and their dosage) were not changed or their 1.5-2-fold dose tapering was attested compared to the same before treatment using FSCs.

A number of clinical studies have been recently performed in world diabetes science which conclusively shown and proved the provisions on the principal factors contributing to T2DM progression and appearance of severe disease complications $[1,4,9,12,13]$. Precise targets 
Citation: Demchuk MP, Ivankova O, Klunnyk M, Matiyashchuk I, Sych N, et al. (2016) Efficacy of Fetal Stem Cells use in Complex Treatment of Patients with Insulin-resistant Type 2 Diabetes Mellitus. J Stem Cell Res Ther 6: 342. doi:10.4172/2157-7633.1000342

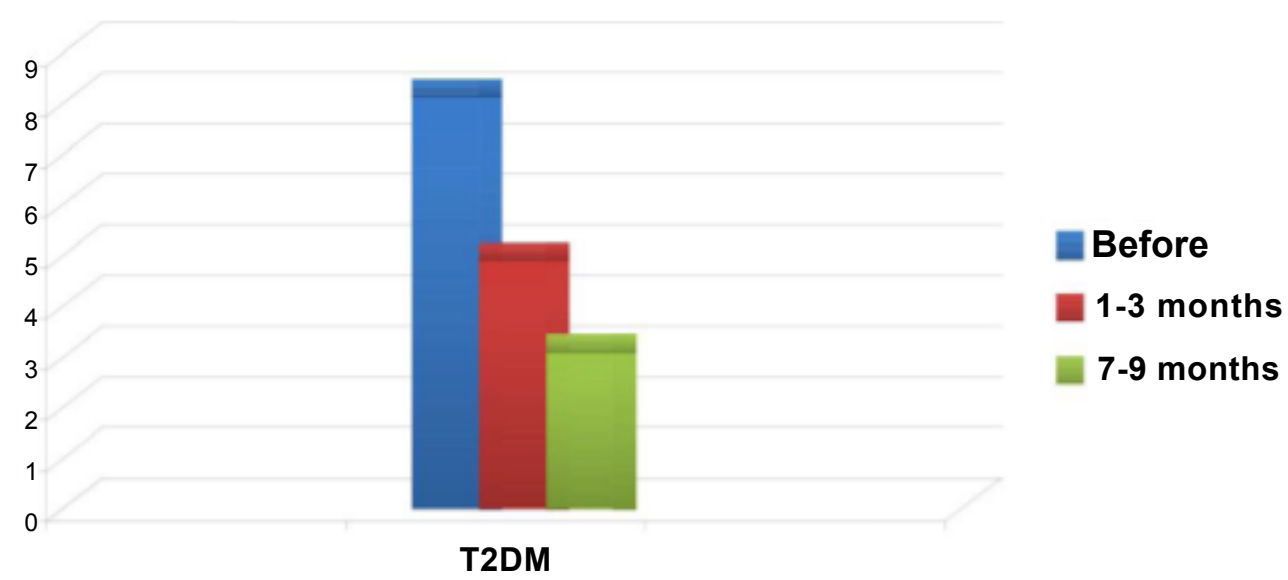

Figure 3: HOMA-IR Dynamics Before- and After FSCs Treatment in Patients with Type 2 DM.

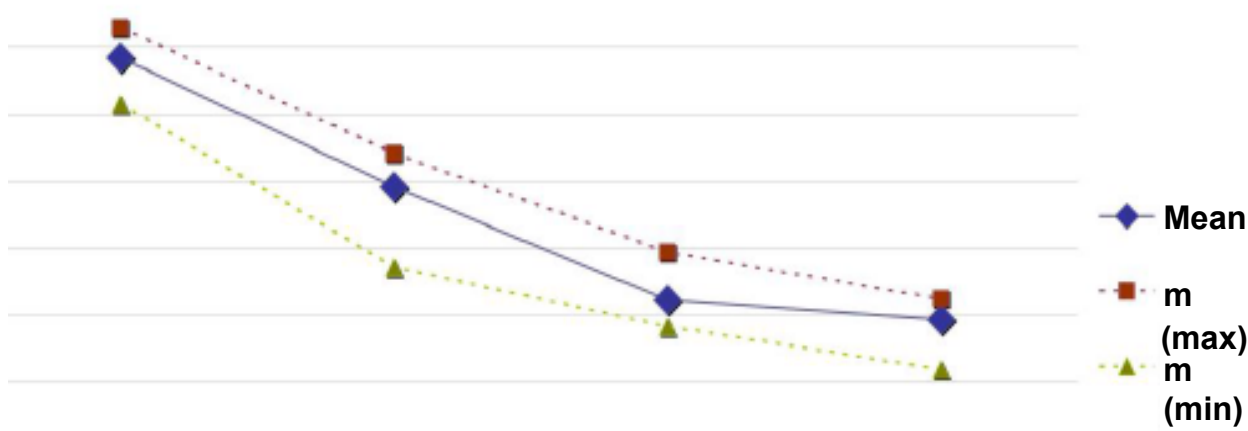
Before FSCT
2-3 months
5-7 months
10-12 months

Figure 4: Serum C-Peptide Dynamics Before- and After FSCs Treatment in Patients with Type 2 DM.

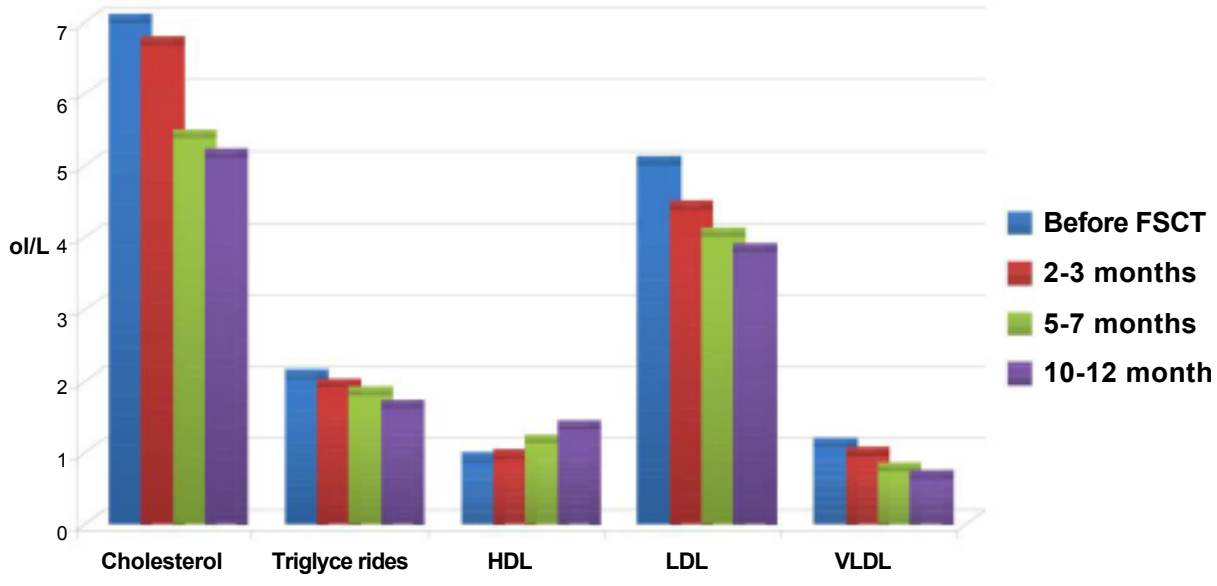

Figure 5: Lipids Dynamics Before- and After FSCs Treatment in Patients with Type 2 DM

of therapy to be achieved in treatment of each patient with T2DM were established accordingly. The levels of glycated hemoglobin, fasting and postprandial blood glucose, lipid profile, arterial blood pressure and body weight are among these principal targets of DM therapy. Owing to presence of pleiotropic action after FSCs administration (persistent improvement of carbohydrates values, lipids metabolism, and 
Citation: Demchuk MP, Ivankova O, Klunnyk M, Matiyashchuk I, Sych N, et al. (2016) Efficacy of Fetal Stem Cells use in Complex Treatment of Patients with Insulin-resistant Type 2 Diabetes Mellitus. J Stem Cell Res Ther 6: 342. doi:10.4172/2157-7633.1000342

Page 6 of 7

\begin{tabular}{c|c|c|c|}
\hline Parameters & Before FSCT & over 3 months & over 12 months \\
\hline SBP, $\mathrm{mm} . \mathrm{Hg}$. & $164.3 \pm 12.3$ & $135.4 \pm 10.7$ & $124.3 \pm 12.2^{*}$ \\
\hline DBP, $\mathrm{mm} . \mathrm{Hg}$. & $92.1 \pm 9.6$ & $87.9 \pm 9.1$ & $78.1 \pm 9.8^{*}$ \\
\hline $\begin{array}{c}\text { WC, } \mathrm{cm} \\
\text { M }\end{array}$ & $113.24 \pm 10.65101 .24$ & $111.61 \pm 12.34$ & $106.38 \pm 12.74^{*}$ \\
W & \pm 9.73 & $98.54 \pm 10.26$ & $93.57 \pm 8.34^{*}$ \\
\hline BMI, $\mathrm{kg} / \mathrm{m}^{2}$ & $34.49 \pm 2.81$ & $32.61 \pm 1.63$ & $31.64 \pm 1.57^{*}$ \\
\hline
\end{tabular}

Table 2: Hemodynamic and anthropometric parameters in patients with T2DM before and after FSCs treatment.

hemodynamic rates etc.) recorded during this study, administration of FSCs in complex treatment of patients with T2DM is justified as clinically effective and reliable method of treatment.

\section{Conclusion}

Use of fetal stem cells in combined treatment of the patients with T2DM is a safe and effective method which contributes to compensation of carbohydrates and lipids metabolism in the patients. The following significant clinical effects of FSCs have been observed:

1. Syndrome of early post-transplantation improvements. Favorable changes in overall physical and emotional states were reported in $85.7 \%$ of the patients.

2. Hypoglycemic effect. Gradual decrease of fasting blood glucose, postprandial glycaemia and $\mathrm{HbAlc}$ has been observed in all patients over 2-3 months after FSCs treatment with significant lowering over 5-7 months and preserved effects of treatment up to 12 months. Volume of antihyperglycemic therapy remained unchanged in $35.7 \%$ of patients or treatment required 1.5 -2-fold doses taper (in $64.3 \%$ of patients). No marked hypoglycemic states were reported among the patients.

3. Hypolipidemic effect. $81 \%$ of patients revealed lower levels of total cholesterol, TG, LDL and VLDL cholesterol values - over 20-24\%, and elevation of HDL cholesterol by $21-25 \%$ over 10-12 months after treatment opposite to lack of any positive advantages after previous lipid-lowering therapy.

4. Lower insulin-resistance. Systematic decrease of hyperinsulinemia within 1-3 months after FSCs administration and lower HOMA-IR rates were observed in $92.9 \%$ of patients: over $2-3$ months after treatment 1.5-1.7-fold decrease was reported, which reached its maximal low rates over 5-7 months - 2.4-2.6-fold decrease. Reduction of insulinresistance value that has been proved by laboratory parameters and clinical markers of IR (i.e. reduced excessive body weight and less waist circumference) we can refer to as the principal mechanisms over which fetal stem cells induce their blood glucose and lipids lowering effects.

\section{References}

1. International Diabetes Federation

2. (2015) World Health Organization. Geneva: WHO. [PubMed]

3. Tao Z, Shi A, Zhao Z (2015) Epidemiological perspectives of diabetes. Cell. Biochem. Biophys 25: 41-43. [PubMed]

4. Stratton I, Adler A, Neil A, Matthews D, Manley S, et al. (2000) Association of glycaemia with macrovascular and microvascular complications of type 2 diabetes (UKPDS 35): prospective observational study 321: 405-412.[PubMed]

5. Hanley AJ, Karter AJ, Williams K, Festa A, D'Agostino RB, et al. (2005) Prediction of type 2 diabetes mellitus with alternative definitions of the metabolic syndrome: the Insulin Resistance Atherosclerosis Study. Circulation 112: 37133721.[PubMed]

6. Taylor KS, Heneghan CJ, Farmer AJ, Fuller AM, Adler Al, et al. (2013) Allcause and cardiovascular mortality in middle-aged people with type 2 diabetes compared with people without diabetes in a large U.K. primary care database. Diabetes Care 36: 2366-2371.[PubMed]

7. Bonora E, Kiechl S, Willeit J, Oberhollenzer F, Egger G, et al. (1998) Prevalence of insulin resistance in metabolic disorders: the Bruneck Study. Diabetes 47: 1643-1649.[PubMed]

8. (2000) Ginsberg HN. Insulin resistance and cardiovascular disease. J Clin Invest. 106: 453-458.[PubMed]

9. Sarwar N, Gao P, Seshasai SRK, Gobin R, Kaptoge S, et al. (2010) Diabetes mellitus, fasting blood glucose concentration, and risk of vascular disease: a collaborative meta-analysis of 102 prospective studies. Lancet 375: 22152222.[PubMed]

10. Boada C, Martínez-Moreno J (2013) Pathophysiology of diabetes mellitus type 2: beyond the duo "insulin resistance-secretion deficit". Nutr Hosp 28: 7887.[PubMed]

11. Pankiv VI (2007) Diabetes mellitus, prediabetes and cardiovascular disease Practical angiology 1: 4-10.

12. (2001) Executive Summary of the Third Report of the National Cholestero Education Program (NCEP) Expert Panel on Detection, Evaluation, and Treatment of High Blood Cholesterol in Adults (Adult Treatment Panel III) JAMA 285: 2486-2497.[PubMed]

13. (2011) American Diabetes Association. Standard of medical care in diabetes. Diabetes care 34: 11- 61.[PubMed]

14. Efimov AS, Smicodub Al, Novitskaya AV. Pharmaceutical preparation with immuno-correcting properties based on a cell suspension, and a method of treating sugar diabetes using said preparation Priority.

15. Shiroi A, Yoshikawa M, Yokota H, Fukui H, Ishizaka S, et al. (2002) Identification of insulin-producing cells derived from embryonic stem cells by zinc-chelating dithizone. Stem Cells 20: 284-292.[PubMed]

16. (2003) Process for the preparation of medicinal compositions for the treatment of diabetes. Smicodub Novits'kaya AV.

17. Novytska AV, Smikodub OI, Efimov AS (1998) Use of fetal stem cel suspensions in diabetes mellitus patients. Materials of the 14th Congress of Therapeutists of Ukraine. Kyiv 554-556.

18. Novytska AV (1994) Clinical case of treatment for early diagnosed disease of type 1 diabetes mellitus using hematopoietic fetal liver stem cells of human. Modern problems of experimental and clinical endocrinology 126-127.

19. Novytskaja A, Smikodoub A (1996) Treatment of patients with initially revealed insulindependent sugar diabetes with the use of fetal cell suspensions. Minimally Invasive Therapy \& Allied Technologies 5: 117.

20. Novytska AV (1999) Use of hematopoietic human fetal stem cells in anemic syndrome treatment in patients diabetes complicated by diabetic glomerulosclerosis and chronic kidney failure.Ukrainian scientific medical youth journal 1: 36-40.

21. Efimov AS, Smikodub OI, Novytska AV (2002) Transplantation of hematopoietic human fetal cells to the patients with type 1 diabetes mellitus.; Transplantology 3: $26-31$.

22. Novytska AV, Smikodub OI (2003) Treatment of patients with type 1 diabetes using stem cells suspensions Transplantology 4: 172-174.

23. Smikodub OI, Novytska AV (2006) Embryonic Cell Suspensions in Pernicious Decompensated Type 2 Diabetes Mellitus. Cytotherapy 8: 93.

24. Smikodub OI, Novytska AV (2004) Use of fetal stem cells in treatment of patients with type 2 diabetes mellitus. Transplantology 7: 360-363.

25. Novytska AV, Smikodub OI, Demchuk MP, Arkhypenko IV (2010) Fetal stem cells in treatment of metabolic syndrome. Cells Transplantology and Tissue Engineering 5: 43-44.

26. (1999) World Health Organization. Definition, diagnosis and classification of diabetes mellitus and its complications. Part 1: diagnosis and classification of diabetes mellitus (Report of the WHO Consultation). Geneva: WHO.

27. Smikodub OI, Arkhypenko, Bushnieva VO, Demchuk MP, Novytska AV, et al (2004) Ethical issues and standards in work with human embryonic tissues: Method. Recommendations at the Ministry of Health of Ukraine. Kyiv 20.

28. (2000) Treatment of patient with primary insulin-dependent diabetes mellitus by use of hematopoietic stem cells extracted from fetal liver: Methodology 
Citation: Demchuk MP, Ivankova O, Klunnyk M, Matiyashchuk I, Sych N, et al. (2016) Efficacy of Fetal Stem Cells use in Complex Treatment of Patients with Insulin-resistant Type 2 Diabetes Mellitus. J Stem Cell Res Ther 6: 342. doi:10.4172/2157-7633.1000342

recommendations at the Ministry of Health of Ukraine, Academy of Medical Science of Ukraine, and Ukrainian Center for Scientific Medical Information and Patent Licensing Activity. Kyiv 14

29. (2012) International Diabetes Federation. Global Guideline for Type 2 Diabetes. IDF 117 .

30. Matthews D, Hosker J, Rudenski A, Naylor BA, Treacher DF, et al. (1985) Homeostasis model assessment: insulin resistance and beta-cell function from fasting plasma glucose and insulin concentrations in man. Diabetologia 28: 412-419.[PubMed]

31. Friedewald WT, Levy RI, Fredrickson DS (1972) Estimation of the concentration of low-density lipoprotein cholesterol in plasma, without use of the preparative ultracentrifuge. Clin Chem 18: 499-502.[PubMed]
32. (1998) Effect of intensive blood-glucose control with metformin on complications in overweight patients with type 2 diabetes (UKPDS 34). Lancet 352: 854-865. [PubMed]

33. Haffner SM, Despres JP, Balkau B, Wittchen HU, Massien C, et al. (2006) Waist circumference and body mass index are both independently associated with cardiovascular disease: The International Day for the Evaluation of Abdominal Obesity (IDEA) survey. J Am Coll Cardiol $4: 842-846$. [PubMed]

34. Gerstein HC, Miller ME, Probstfield JL, Simons-Morton DG, Friedewald WT, et al. (2008) Action to Control Cardiovascular Risk in Diabetes Study Group, Effects of intensive glucose lowering in type 2 diabetes.N. Engl. J. Med 358: 2545-2559.[PubMed] 